Original Article

\title{
Effects of the application of ankle functional rehabilitation exercise on the ankle joint functional movement screen and isokinetic muscular function in patients with chronic ankle sprain
}

\author{
Sung-Bum Ju, PhD ${ }^{1)}$, Gi Duck PARK, $\mathrm{PhD}^{2}$ * $^{*}$ \\ 1) Major in Exercise Therapy, Department of Sport and Health Care, Namseoul University, \\ Republic of Korea \\ 2) Department of Leisure and Sports, Kyungpook National University: 386 Gajangdong, Sangju \\ 742-711, Republic of Korea
}

\begin{abstract}
Purpose] This study was conducted to investigate the effects of ankle functional rehabilitation exercise on ankle joint functional movement screen results and isokinetic muscular function in patients with chronic ankle sprain patients. [Subjects and Methods] In this study, 16 patients with chronic ankle sprain were randomized to an ankle functional rehabilitation exercise group $(n=8)$ and a control group $(n=8)$. The ankle functional rehabilitation exercise centered on a proprioceptive sense exercise program, which was applied 12 times for 2 weeks. To verify changes after the application, ankle joint functional movement screen scores and isokinetic muscular function were measured and analyzed. [Results] The ankle functional rehabilitation exercise group showed significant improvements in all items of the ankle joint functional movement screen and in isokinetic muscular function after the exercise, whereas the control group showed no difference after the application. [Conclusion] The ankle functional rehabilitation exercise program can be effectively applied in patients with chronic ankle sprain for the improvement of ankle joint functional movement screen score and isokinetic muscular function.

Key words: Ankle sprain, Functional rehabilitation, Joint functional movement screen
\end{abstract}

(This article was submitted Aug. 31, 2016, and was accepted Nov. 7, 2016)

\section{INTRODUCTION}

Ankle sprain occurs more often in active movements such as walking, running, and jumping. Among lower limb injuries, ligament injuries of the ankle account for more than $50 \%$ of the cases. Furthermore, at least $7 \%$ of people with ankle sprain had additional repetitive symptoms, including re-injuries and functional anomalies ${ }^{1)}$. Re-injury of ankle sprain triggers chronic ankle instability (CAI), which acts as a cause for recurrent sprains in $55-72 \%$ of the cases. These patients with reinjuries complained of residual symptoms for 6 to 18 months ${ }^{2}$. In this way, many previous studies reported a high recurrence rate of ankle sprain ${ }^{3,4)}$ and attributed the causes of this high recurrence rate to deformed tissues around the ankle joint, loss of proprioceptive sense ${ }^{5)}$, and reuse of the ankle joint before complete recovery. Such repetitive injuries lead to functional ankle and chronic ankle joint instabilities ${ }^{2)}$. Thus, chronic ankle sprain is highly correlated with chronic ankle joint instability. CAI refers to the repetition of lateral ankle joint instability after an initial lateral ankle ligament sprain, with residual symptoms such as pain, edema, and giving way of the ankle joint ${ }^{6}$. Furthermore, the greatest causes of repetitive ankle sprain were reported to be the muscular weakness of the tibialis anterior and peroneus longus, and the increased ankle instability due to

\footnotetext{
*Corresponding author. Gi Duck Park (E-mail: prescrip@knu.ac.kr)

C2017 The Society of Physical Therapy Science. Published by IPEC Inc.

This is an open-access article distributed under the terms of the Creative Commons Attribution Non-Commercial No Derivatives (by-nc-nd) License $<$ http://creativecommons.org/licenses/by-nc-nd/4.0/>.
} 
the hypofunction of the proprioceptive sense ${ }^{7,8)}$. In addition, when the instability of the ankle joint increases, other motion patterns are required to compensate for the instability, which causes the motion deformations of the hip joint and trunk, resulting in the side effect of the changed anatomical arrangement ${ }^{9}$. Kim Eun-Kyung ${ }^{10)}$ claimed that rehabilitation exercise treatment programs such as muscle strengthening, kidney, and proprioceptive sense enhancement exercises are required to prevent and treat the chronic pain and functional ankle joint instability after ankle joint sprain. A rehabilitation exercise through 4-week balance training has been also reported to elicit significant changes in the lower leg rotation and hindfoot angle ${ }^{11)}$. O'driscoll et al. ${ }^{12)}$ reported that functional rehabilitation exercises for 6 weeks, including muscle-strengthening exercise, balancing exercise, and agility and jump training caused significant changes in balancing ability and hindfoot angle. Therefore, an appropriate functional rehabilitation program should be applied to improve chronic ankle joint instability by reinforcing the muscular function of the ankle joint and enhancing the proprioceptive sense in patients with chronic ankle sprain. Hence, in this study, an ankle functional rehabilitation exercise was applied to patients with chronic ankle sprain and its effects on ankle joint FMS result and isokinetic muscular function were examined. This presents a new alternative to the functional rehabilitation exercise program for the prevention and rehabilitation of ankle sprain for patients with chronic ankle sprain.

\section{SUBJECTS AND METHODS}

The subjects of this study were 16 patients with chronic ankle pain and chronic ankle sprain whose chronic CAI had been diagnosed by medical examination, simple radiological examination, computed tomography, and magnetic resonance imaging. They were randomized to the ankle functional rehabilitation exercise group (AFREG; $n=8$ ) and control group (CONG; $\mathrm{n}=8$ ). For the physical characteristics of the subjects, the mean age, height, and weight of the AFREG were $20.8 \pm$ 0.5 years, $174.6 \pm 7.1 \mathrm{~cm}$, and $69.6 \pm 9.03 \mathrm{~kg}$. Those of the CONG were $20.7 \pm 1.1$ years, $174.1 \pm 6.5 \mathrm{~cm}$, and $66.2 \pm 7.6 \mathrm{~kg}$. After receiving an explanation of the intent and purpose of this study, they voluntarily agreed to participate in this study. The two groups had no problem in homogeneity because they had no significant intergroup differences in physical characteristics. The ankle functional rehabilitation exercise program mainly consisted of a proprioceptive sense exercise program, which was performed in a total of 12 times, 6 times per week for 2 weeks, with an exercise time of 60 minutes. The ankle functional rehabilitation exercise program used the exercise tools for proprioceptive sense exercise, Jumper (TOGU, Germany) and Togu (TOGU, Germany). In detail, the exercise items were (1) balance squat and (2) supine pelvic lift, performed while standing on the jumper, and (3) lunge and (4) dorsi and plantar flexion, performed by weight bearing while standing on the Togu. The exercise time was maintained at 30 seconds per set, during which isometric training was performed. For the FMS related to ankle joint, deep squat, hurdle step, and in-line lunge tests were performed in relation to the ankle joint functional movement in 7 patterns by using the FMS test kit (USA), which is a functional motion inspection measurement system. For the ankle joint isokinetic muscular function inspection, the peak torque (Nm) at the angular speed of $240^{\circ}$ was measured by using Cybex Humac Norm (Ankle Joint System, USA). The measured data were analyzed by using the SPSS 21.0 statistical program for Windows. A paired-test was conducted for comparison of the groups between before and after the application. The significance level was set at $\alpha=0.05$.

All of the subjects understood the purpose of this study and provided written informed consent prior to their participation in accordance with the ethical standards of the Declaration of Helsinki.

\section{RESULTS}

In the ankle joint FMS, the AFREG showed significant improvements in all the FMS items after application $(\mathrm{p}<0.05)$, and the CONG did not show any significant changes after the application (Table 1).

For changes in the ankle joint isokinetic muscular functions, the AFREG showed significant improvements in every item after application $(\mathrm{p}<0.05)$, whereas CONG did not show any significant changes after application (Table 2).

Table 1. The comparison of ankle joint of FMS in the each group (unit: Nm)

\begin{tabular}{lccc}
\hline Group & Muscle strength & Pre $($ Mean \pm SD) & Post (Mean \pm SD) \\
\hline \multirow{3}{*}{ AFREG } & DST $^{*}$ & $1.6 \pm 0.5$ & $2.5 \pm 0.5$ \\
& HST $^{*}$ & $1.8 \pm 0.3$ & $2.7 \pm 0.4$ \\
& ILT $^{*}$ & $2.0 \pm 0.0$ & $2.8 \pm 0.3$ \\
CONG & DST & $1.7 \pm 0.4$ & $1.7 \pm 0.4$ \\
& HST & $1.8 \pm 0.3$ & $2.1 \pm 0.9$ \\
& ILT & $2.0 \pm 0.0$ & $2.3 \pm 0.5$ \\
\hline
\end{tabular}

$*_{p}<0.05$; AFREG: ankle functional rehabilitation exercise group; CONG: control group; DST: deep squat test; HST: hurdle step test; ILT: in-line lunge test 


\section{DISCUSSION}

The CAI generates structural changes of the soft tissues around the ankle due to repetitive ankle sprains and causes dysfunction in the stability of ankle neuromuscular control and in musculoskeletal stability ${ }^{13)}$. Among the problems in patients with chronic ankle sprain are decreased function of the proprioceptive sense and decreased reaction speed ${ }^{14)}$. Furthermore, Scott ${ }^{15)}$ reported that functional rehabilitation exercise more effectively reduced pain and edema than surgery and fixation. Another previous study also reported that functional rehabilitation exercise through the training of proprioceptive sense decreased the re-injury rate of the ankle ${ }^{16}$ ). Recently, active research is being conducted to present the directions of functional rehabilitation exercise, and studies on the evaluation of functional rehabilitation exercise are being conducted as well ${ }^{17}$.

This study was conducted to demonstrate that chronic ankle sprain is caused by chronic dysfunction and instability of the ankle joint, and the muscular function and stability of the ankle joint were improved through the application of ankle functional rehabilitation exercise.

The AFREG showed significant improvements in all items of the FMS and ankle joint isokinetic muscular function after application $(\mathrm{p}<0.05)$, whereas the CONG showed no significant changes after application. The FMS (Functional Movement Screen) is known to be useful for evaluating asymmetries of the body and defects in functional exercise motions based on the basic motions of the proprioceptive sensory receptor, stability, and mobility, which are the motion patterns of the body ${ }^{18,19)}$. Thus, it was used as a measurement item in this study.

In this study, by using this FMS evaluation method, the functional defects of the ankle were chosen as the measurement items before and after exercise. Furthermore, the isokinetic measuring instrument is an effective tool for evaluating muscular function because it can produce the maximum muscular force according to the resistance within the predefined range of motion of the joint. It is used to examine the effects of diagnosis and rehabilitation exercise programs ${ }^{20)}$. Hence, in this study, an isokinetic instrument was used to measure the effects of the functional rehabilitation exercise program on the improvement of muscular functions.

Functional rehabilitation exercise is an integrated form of training for muscular strength, agility, proprioceptive sense, and special exercise functions and refers to various patterns of exercise programs. It has been shown to effectively decrease pain and dysfunction. Furthermore, it has the effect of protecting tissues from many physical burdens applied during physical activities by increasing the reaction speed of surrounding muscles and nerve tissues, restoring stability, and reinforcing muscles $^{21)}$.

In addition, an 8-week functional rehabilitation program, including proprioceptive exercise, helped the stabilization of the unstable ankle joint by improving postural sway and isokinetic muscular function (isokinetic strength) ${ }^{22}$. An ankle joint balance improvement exercise program was effective in the rehabilitation and prevention of chronic ankle instability and sprain, and the control of proprioceptive ability protected the body from injuries ${ }^{11)}$.

In the application of rehabilitation exercise program for resolving functional ankle instability, the combined application of muscle strengthening and proprioceptive exercises was more effective than muscle strengthening exercise alone ${ }^{22)}$. Besides, because ankle instability is caused by the combination of the lack of proprioceptive sense and eversion muscle weakening, rehabilitation programs must focus on the improvement of the proprioceptive sense and muscular strength ${ }^{23)}$. Furthermore, both improved proprioceptive sensibility and the functional capabilities of the surrounding muscles of the ankle joints, thereby providing a coping mechanism for the unexpected inversion of ankle joints ${ }^{24)}$.

Therefore, the ankle functional rehabilitation program applied in this study was mainly composed of the exercise of proprioceptive sense in order to achieve the stability of the affected site by recovering the motion control ability while reinforcing the muscular strength of the patients with chronic ankle sprain. The improvement was achieved as a result of the improved muscular functions of the muscles comprising the ankle joint and the improved integrated system of the muscles

Table 2. The comparison of ankle joint of peak torque in the each group (unit: Nm)

\begin{tabular}{lccc}
\hline Group & Muscle strength & Pre $($ Mean \pm SD) & Post $($ Mean \pm SD) \\
\hline \multirow{4}{*}{ AFREG } & ADFR* & $27.2 \pm 6.9$ & $34.7 \pm 12.4$ \\
& ADFL* & $25.5 \pm 7.0$ & $33.7 \pm 9.7$ \\
& APFR* & $41.6 \pm 14.4$ & $64.6 \pm 9.8$ \\
& APFL* & $40.1 \pm 13.8$ & $59.2 \pm 13.0$ \\
CONG & ADFR & $31.0 \pm 10.6$ & $28.1 \pm 7.0$ \\
& ADFL & $28.7 \pm 10.1$ & $29.1 \pm 8.1$ \\
& APFR & $38.6 \pm 11.3$ & $50.8 \pm 19.0$ \\
\hline
\end{tabular}

${ }^{*} \mathrm{p}<0.05$; AFRE: ankle functional rehabilitation exercise group; CONG: control group; ADFR: ankle dorsi flexion right; ADFL: ankle dorsi flexion left; APFR: ankle plantar flexion right; APFL: ankle planter flexion left 
and nerves that support balance and enables the exhibition of stable forces through the integration of the proprioceptive receptor and motion sensory nerves by the muscles around the trunk, pelvis, and abdomen.

Consequently, the application of ankle functional rehabilitation exercise in patients with chronic ankle sprain in this study will present a new alternative solution as an effective rehabilitation program for the reinforcement of ankle joint FMS and isokinetic muscular function.

\section{ACKNOWLEDGEMENT}

This research was supported by Kyungpook National University Bokhyeon Research Fund, 2015.

\section{REFERENCES}

1) Anandacoomarasamy A, Barnsley L: Long term outcomes of inversion ankle injuries. Br J Sports Med, 2005, 39: e14, discussion e14. [Medline] [CrossRef]

2) Wikstrom EA, Tillman MD, Chmielewski TL, et al.: Dynamic postural stability deficits in subjects with self-reported ankle instability. Med Sci Sports Exerc, 2007, 39: 397-402. [Medline] [CrossRef]

3) Beynnon BD, Murphy DF, Alosa DM: Predictive factors for lateral ankle sprains; a literature review. J Athl Train, 2002, 37: 376-380. [Medline]

4) Klein J, Höher J, Tiling T: Comparative study of therapies for fibular ligament rupture of the lateral ankle joint in competitive basketball players. Foot Ankle, 1993, 14: 320-324. [Medline] [CrossRef]

5) Eun-Young L: The Effects of 8 weeks CAI rehabilitation program on improvement of ankle strength and power. Ewha Womens University Dissertation, 2004.

6) Morrison KE, Kaminski TW: Foot characteristics in association with inversion ankle injury. J Athl Train, 2007, 42: 135-142. [Medline]

7) Lentell G, Baas B, Lopez D, et al.: The contributions of proprioceptive deficits, muscle function, and anatomic laxity to functional instability of the ankle. J Orthop Sports Phys Ther, 1995, 21: 206-215. [Medline] [CrossRef]

8) Kaminski TW, Buckley BD, Powers ME, et al.: Effect of strength and proprioception training on eversion to inversion strength ratios in subjects with unilateral functional ankle instability. Br J Sports Med, 2003, 37: 410-415, discussion 415. [Medline] [CrossRef]

9) Gross MT: Effects of recurrent lateral ankle sprains on active and passive judgements of joint position. Phys Ther, 1987, 67: 1505-1509. [Medline]

10) Kyung KE: The effects of proprioceptor training on functional ankle joint instability in soccer players. Korea Sport Res, 2004,15 : 1839-1852.

11) McKeon PO, Ingersoll CD, Kerrigan DC, et al.: Balance training improves function and postural control in those with chronic ankle instability. Med Sci Sports Exerc, 2008, 40: 1810-1819. [Medline] [CrossRef]

12) O’Driscoll J: Kerin F, Delahunt E: Effect of 6-week dynamic neuromuscular training programme on ankle function. Sports Med Arthrosc Rehabil Ther Technol, 2011, 9: 13 .

13) Hartsell HD, Spaulding SJ: Eccentric/concentric ratios at selected velocities for the invertor and evertor muscles of the chronically unstable ankle. Br J Sports Med, 1999, 33: 255-258. [Medline] [CrossRef]

14) Konradsen L, Ravn JB: Ankle instability caused by prolonged peroneal reaction time. Acta Orthop Scand, 1990, 61: 388-390. [Medline] [CrossRef]

15) Ross SE: Noise-enhanced postural stability in subjects with functional ankle instability. Br J Sports Med, 2007, 41: 656-659, discussion 659. [Medline] [CrossRef]

16) Osborne MD, Rizzo TD Jr: Prevention and treatment of ankle sprain in athletes. Sports Med, 2003, 33: 1145-1150. [Medline] [CrossRef]

17) Webster KA, Gribble PA: Functional rehabilitation interventions for chronic ankle instability: a systematic review. J Sport Rehabil, 2010, 19: 98-114. [Medline] [CrossRef]

18) Cook G, Burton L, Hoogenboom B: Pre-participation screening: the use of fundamental movements as an assessment of function -part 1. N Am J Sports Phys Ther, 2006, 1: 62-72. [Medline]

19) Minick KI, Kiesel KB, Burton L, et al.: Interrater reliability of the functional movement screen. J Strength Cond Res, 2010, 24: 479-486. [Medline] [CrossRef]

20) Armour T, Forwell L, Litchfield R, et al.: Isokinetic evaluation of internal/external tibial rotation strength after the use of hamstring tendons for anterior cruciate ligament reconstruction. Am J Sports Med, 2004, 32: 1639-1643. [Medline] [CrossRef]

21) Hyoung HK: [Effects of a strengthening program for lower back in older women with chronic low back pain]. J Korean Acad Nurs, 2008, 38: 902-913. [Medline] [CrossRef]

22) Kim KJ, Kim YE, Jun HJ, et al.: Which treatment is more effective for functional ankle instability: strengthening or combined muscle strengthening and proprioceptive exercises. J Phys Ther Sci, 2014, 26: 385-388. [Medline] [CrossRef]

23) McKeon PO, Hertel J: Systematic review of postural control and lateral ankle instability, part II: is balance training clinically effective? J Athl Train, 2008, 43 : 305-315. [Medline] [CrossRef]

24) Nam SM, Kim WB, Yun CK: Effects of balance training by knee joint motions on muscle activity in adult men with functional ankle instability. J Phys Ther Sci, 2016, 28: 1629-1632. [Medline] [CrossRef] 